paranasal sinuses and characteristically invades the walls and lumen of blood vessels. In leukaemic patients it usually also invades lung and sometimes becomes disseminated (Mirsky and Cuttner, 1972; Myer et al., 1972). Any lung lobe can be affected and infarction is common (Medoff and Kobayashi, 1972). The organism is difficult to recover and grow in culture. Frequently the diagnosis is made at necropsy (Krick and Remington, 1976). It is not a common human saprophyte and therefore the presence of mucor hyphae on any biopsy smear must be taken as strong evidence of infection (Myer et al., 1972; Krick and Remington, 1976). This is especially so in a febrile leukaemic patient with a persistent and/or progressive antibiotic resistant pneumonia.

Our patient is thought to be the first child with leukaemia to be successfully treated with amphotericin and surgical resection for extensive rhinopulmonary mucormycosis. We stress the need for aggressive diagnostic procedures, including debridement and resection, in conjunction with adequate amphotericin if this diagnosis is suspected.
We acknowledge the help of Dr A. Yeager and Dr T. Long in preparing this manuscript.

\section{References}

Baker, R. D. (1962). Leukopenia and therapy in acute leukemia as factors predisposing to fatal mycosis. American Journal of Clinical Pathology, 37, 358-373.

Harris, J. S. (1955). Mucormycosis. Pediatrics, 16, 857-867.

Hughes, W. T. (1971). Fatal infections in childhood leukemia. American Journal of Diseases of Children, 122, 283-287.

Krick, J. A., and Remington, J. S. (1976). Opportunist invasive fungal infections in patients with leukaemia and lymphoma. Clinics in Haematology, 5, 249-310.

McBride, R. A., Corson, J. M., and Dammin, G. J. (1960). Mucormycosis. American Journal of Medicine, 28, 832-846.

Medoff, G., and Kobayashi, G. S. (1972). Pulmonary mucormycosis. New England Journal of Medicine, 286, 86-87.

Mirsky, H.S., and Cuttner, J. (1972). Fungal infection in acute leukemia. Cancer, 30, 348-352.

Myer, R. D., Rosen, P., and Armstrong, D. (1972). Phycomycosis complicating leukemia and lymphoma. Annals of Internal Medicine, 77, 871-879.

Correspondence to $\mathrm{Dr}$ O. B. Eden, Department of Child Life and Health, Edinburgh University, Edinburgh, Scotland.

\title{
Neonatal aspergillosis accompanying fulminant necrotising enterocolitis
}

\author{
HENRY H. MANGURTEN AND BALBINO FERNANDEZ
}

Departments of Paediatrics (Section of Neonatology) and Pathology, Lutheran General Hospital, Illinois

SUMMARY A preterm infant developed fulminant necrotising enterocolitis, subsequently resulting in death. Necropsy examination showed diffuse aspergillosis. Reports are reviewed, and possible mechanisms resulting in Aspergillus infection in this infant are discussed.

Disseminated aspergillosis in all age groups is almost always associated with an underlying chronic illness or other predisposing factors-such as prolonged administration of antibiotics or corticosteroids (Zimmerman, 1955; Luke et al., 1963; Riley, 1972). The Aspergillus is a fungus which rarely causes disease in humans. In children, particularly during the neonatal period, aspergillosis is exceedingly rare (Allan and Andersen, 1960; Luke et al., 1963). We recently unexpectedly discovered diffuse aspergillosis in a preterm infant dying from fulminant necrotising enterocolitis (NEC). We can find only five reports (see Table) of neonatal aspergillosis (Zimmerman, 1955; Akkoyunlu and Yucel, 1957;
Allan and Andersen, 1960; Matturri and Fasolis, 1962; Luke et al., 1963). We can find no previous report of this organism in association with NEC. Accordingly we describe our findings.

\section{Case report}

A 950-g boy was born by caesarean section to a 25-year-old primigravid mother after 31 weeks' gestation. Membranes ruptured spontaneously 32 days before delivery. The mother was observed in the hospital for 4 days and discharged home to rest in bed. She was readmitted 2 weeks before delivery because of peptic ulcer disease. She was treated with diazepam, diphenoxylate-hydrochloride with atropine sulphate, trimethobenzamide hydrochloride, acetaminophen, chlordiazepoxide hydrochloride with clidinium bromide, and various antacids. In addition she was given vitamins, secobarbital sodium, diphenhydramine hydrochloride, and iron dextran injection. A cholecystogram was normal. A lecithin/sphinogomyelin (L/S) ratio on amniotic 
Table Reported cases of generalised aspergillosis in neonatal period

\begin{tabular}{|c|c|c|c|c|c|}
\hline Author & $\begin{array}{l}\text { Year } \\
\text { reported }\end{array}$ & $\begin{array}{l}\text { Age at diagnosis } \\
\text { (days) }\end{array}$ & $\begin{array}{l}\text { Distribution of } \\
\text { organism }\end{array}$ & $\begin{array}{l}\text { Method of } \\
\text { diagnosis }\end{array}$ & Predisposing factor(s) \\
\hline Zimmerman & 1955 & 30 & Lungs, brain, liver & $\begin{array}{l}\text { Culture, } \\
\text { necropsy sections }\end{array}$ & $\begin{array}{l}\text { Staph sepsis, antibiotics, } \\
\text { corticosteroids }\end{array}$ \\
\hline Akkoyunlu and Yucel & 1957 & 20 & Lungs, meninges & Culture & Antibiotics \\
\hline Allan and Andersen & 1960 & 18 & $\begin{array}{l}\text { Lungs, liver, heart, } \\
\text { spleen, kidneys, bowel }\end{array}$ & $\begin{array}{l}\text { Culture, } \\
\text { necropsy sections }\end{array}$ & ?None \\
\hline Matturri and Fasolis & 1962 & 37 & $\begin{array}{l}\text { Heart, lungs, thymus, } \\
\text { kidneys, subcutaneous } \\
\text { tissue }\end{array}$ & Necropsy sections & Anal atresia, antibiotics \\
\hline Luke et al. & 1963 & $51^{*}$ & $\begin{array}{l}\text { Heart, kidneys, brain, } \\
\text { blood }\end{array}$ & $\begin{array}{l}\text { Culture, } \\
\text { necropsy sections }\end{array}$ & $\begin{array}{l}\text { Hydrops fetalis, Escherichia } \\
\text { coli sepsis, antibiotics, } \\
\text { chronic inanition }\end{array}$ \\
\hline Present report & 1978 & 16 & Lungs, liver, bowel & $\begin{array}{l}\text { Culture, } \\
\text { necropsy sections }\end{array}$ & $\begin{array}{l}\text { Prematurity, necrotising } \\
\text { enterocolitis, antibiotics }\end{array}$ \\
\hline
\end{tabular}

*Infection related to neonatal problem; infant never left hospital after birth.

fluid collected vaginally 10 days before delivery was $2 \cdot 3 / 1$. Vaginal bleeding and vague uterine contractions developed 2 days before delivery. Ultrasound examination was unrevealing. Several hours before delivery the maternal temperature rose to $37.5^{\circ} \mathrm{C}$, associated with increasing abdominal pain and increase in fetal heart rate. In view of the mature $L / S$ ratio and increasing hazard of infection to mother and fetus, a primary caesarean section was performed under general anaesthesia. Oligohydramnios was noted at delivery. Apgar scores were 7 at one and five minutes. The infant was taken to the high-risk nursery, pink and crying, with mild retractions. Examination of the placenta showed massive subchorionic fibrin deposition.

Physical examination showed a preterm infant who was pink, active, and responsive, with no respiratory distress. The head appeared disproportionately large for the body. Air exchange was fair bilaterally. The skin was dry and peeling, with diminished subcutaneous tissue. Neurological examination showed a fairly good cry and suck, normal tone, and no reaction to Moro's test.

The infant was given maintenance fluids by peripheral vein. Cultures of peripheral blood, urine, and stool were subsequently reported to be negative. At 10 hours nasogastric feedings were started. The first 6 days of life were relatively uneventful, and the infant tolerated gradual formula increases well. On day 7 he developed lethargy, abdominal distention, absent bowel sounds, poor feeding, increasing gastric residue, and grossly bloody stools. Roentgenograms showed evidence of pneumatosis coli. Repeat cultures were taken of blood, urine, and CSF, and ampicillin and gentamicin were started. Feedings were stopped, and nasogastric suctioning was initiated. All repeat cultures were again negative. Frequent serial abdominal $x$-rays showed no change. However, the condition of the infant continued to deteriorate, with bloody stools and progressive apnoea and bradycardia requiring frequent vigorous stimulation. On day 9 he became cyanotic and unresponsive, requiring intubation and respiratory assistance.

On day 13 an upright roentgenogram of the abdomen showed free air under the diaphragm. Platelet count was $3 \cdot 0 \times 10^{9} / 1$, and partial thromboplastin time and prothrombin time were prolonged. Heparin and platelets were given. Exploratory laparotomy showed a recent perforation of the caecum; about $150 \mathrm{ml}$ of serosanguineous fluid was obtained during surgery. Because of the moribund condition of the patient, a loop ileostomy was placed. Cultures of peritoneal fluid subsequently showed an unidentified anaerobe. Accordingly, clindamycin was started, and ampicillin was stopped.

After surgery the infant developed renal failure, followed shortly by rising serum potassium levels. Blood glucose became very labile, ranging from 11 to $1011 \mathrm{mg} / 100 \mathrm{ml}(0.6$ to $0.056 \mathrm{mmol} / \mathrm{l})$. On the last day of life, he developed arrhythmias compatible with hyperkalaemia. His condition gradually deteriorated and he died on day 16. Multiple necropsy cultures showed no growth in cardiac blood or CSF, nor was there growth in either lung or in the tip of endotracheal tube. Clostridium species was recovered from rectum, ileostomy site, and peritoneal fluid; Aspergillus was recovered from the ileostomy site and peritoneal fluid.

\section{Necropsy findings}

Gross description. There were extensive areas of ecchymoses with superficial ulcers. The abdominal cavity contained a scanty amount of dark red fluid. The intestinal loops were distended and dark purple. There was an area of perforation at the base of the appendix; two areas of perforation were present in the descending colon. The liver was enlarged, extending $4 \mathrm{~cm}$ below the right costal margin. There 
were large erosions of the mucosa of the stomach. The brain showed extensive subarachnoid haemorrhage of the left temporal lobe and cerebellum.

Microscopical description (Figs 1 and 2). There was diffuse necrosis of the wall of the small intestine and colon with abundant colonies of Aspergillus infiltrating the wall. Similar findings were observed at the site of the gastric erosions. There was a diffuse bronchopneumonia with extensive infiltrates of Aspergillus. The liver showed areas of necrosis with abundant colonies of Aspergillus.

\section{Discussion}

Neonatal NEC has been described in detail (Pochaczevsky and Kassner, 1971; Stevenson et al., 1971; Frantz et al., 1975). Bacterial infection with resultant peritonitis and septicaemia is a recognised complication of the disease (Hopkins et al., 1970). Infection caused by bacteria or viruses has been considered as one of the aetiological factors, although one report did not give any bacterial, viral, or fungal cause of NEC (Virnig and Reynolds, 1974). Levin and Isaacson (1960) reported a preterm infant who died on day 12 of NEC with resultant perforation and peritonitis; necropsy examination showed fungal hyphae within bowel lumen, wall, and serosa near the site of perforation. Although cultures were not taken, the appearance of the organism was thought to be consistent with mucormycosis. We can find no other report that indicates an association between fungal infection and NEC.

The Aspergillus species is common and rarely causes disease in humans. The organism may be encountered as a contaminant of laboratory cultures. The presence of Aspergillus in multiple sites in this infant-for example stomach, small intestine, liver, and lungs-is strong evidence against laboratory contamination. The patient reported here had a fulminant variety of NEC, with many severe complications (intestinal perforation, peritonitis, possible anaerobic sepsis, disseminated intravascular coagulation, renal failure). This overwhelming form of NEC in association with prematurity possibly compromised him immunologically. The Aspergillus organism is a known 'opportunist'; the chronically ill condition of this preterm infant in association with a severely compromised gastrointestinal tract and broad-spectrum antibiotic therapy resulted in

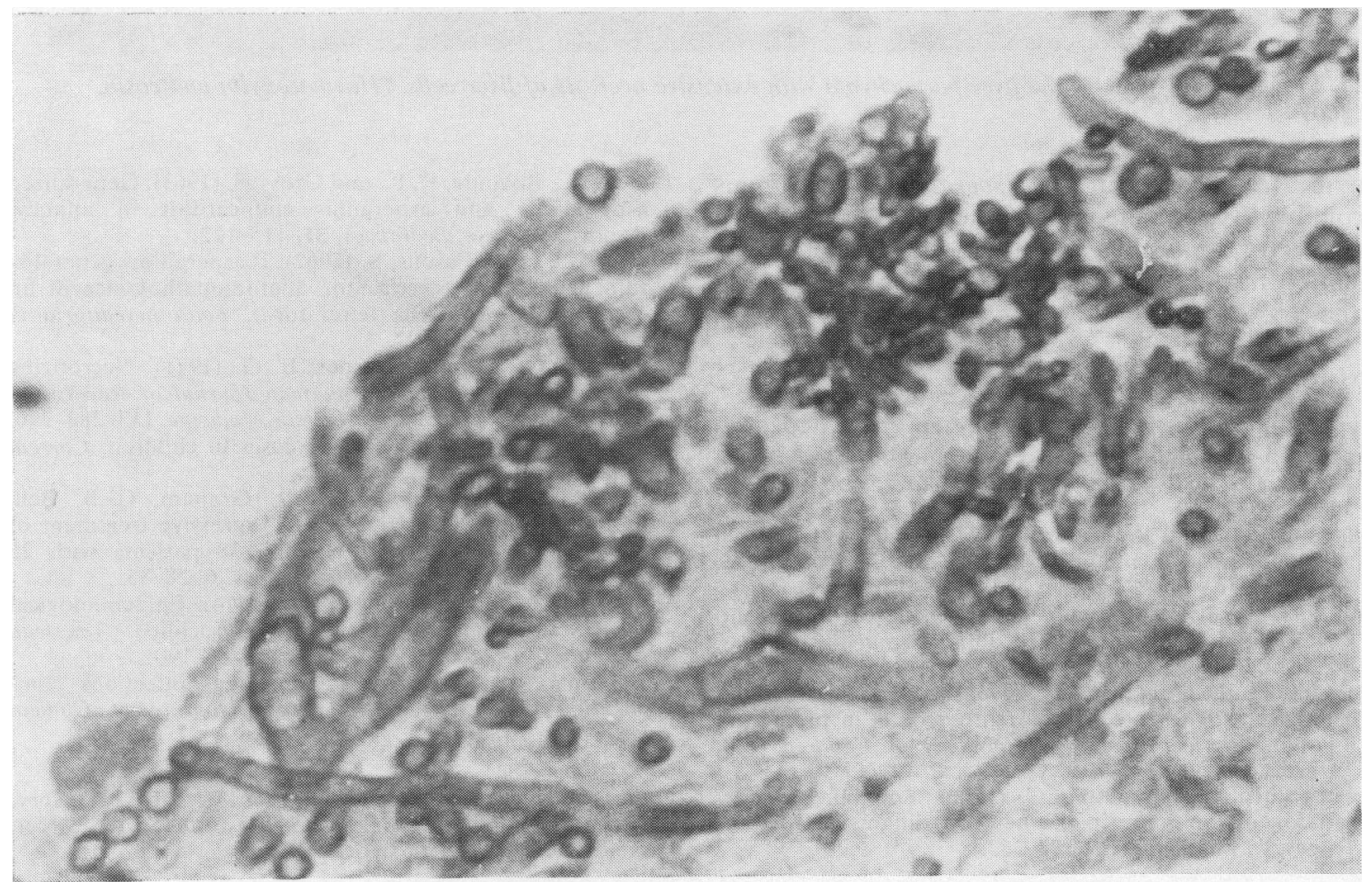

Fig. 1 Section of the ulcerated mucosa of small intestine with abundant growth of Aspergillus. (Haematoxylin and eosin, $\times 400$ ). 


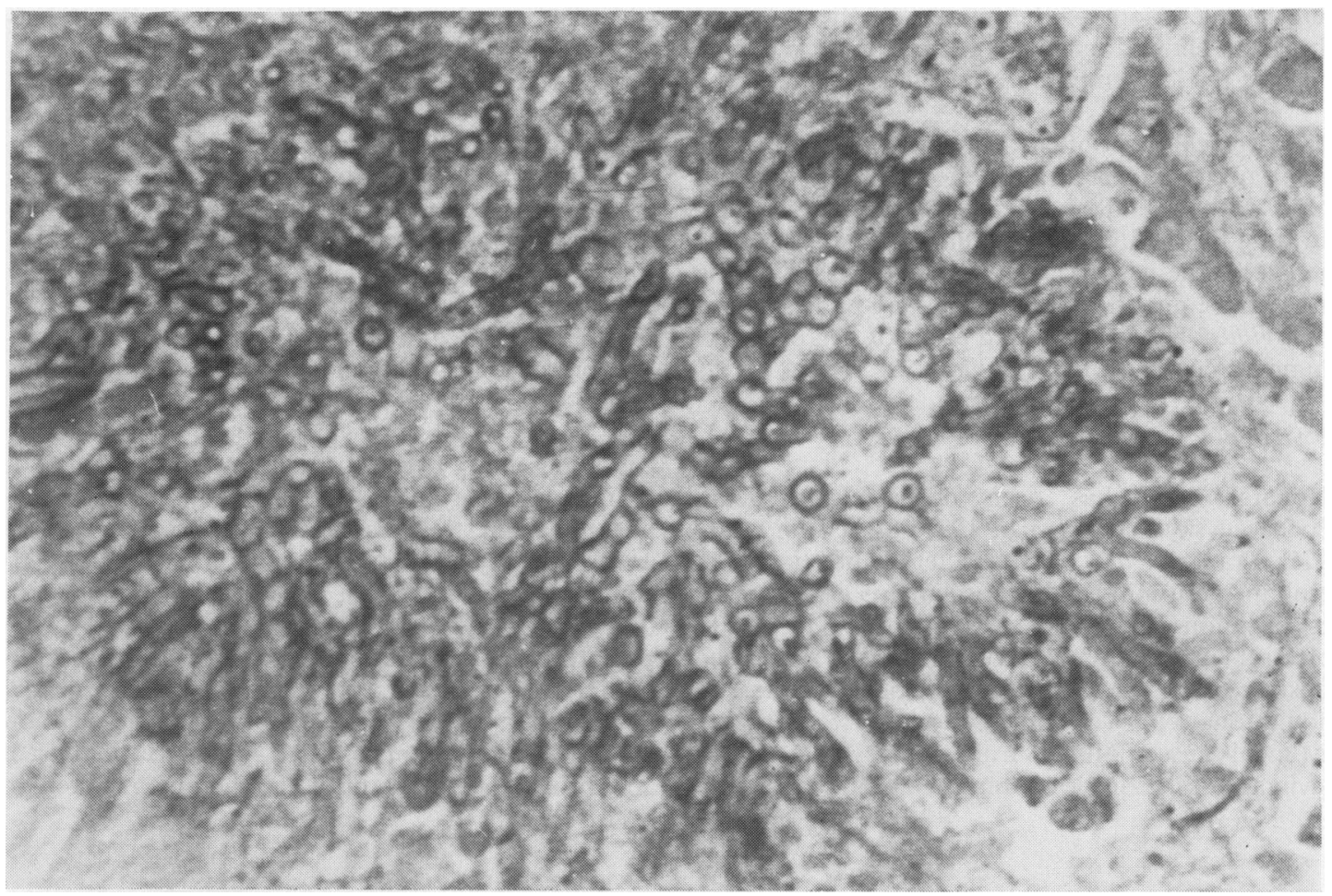

Fig. 2 Mass of hyphae in the liver parenchyma with extensive necrosis of liver cells. (Haematoxylin and eosin, $\times 400$ ).

an ideal environment for Aspergillus. The fungus probably invaded the wall of the ulcerated stomach and necrotic intestine, extending via the portal circulation to the liver and subsequently via the blood stream to the lungs.

\section{References}

Akkoyunlu, A., and Yucel, F. A. (1957). Aspergillose broncho-pulmonaire et encéphalo-meningée chez un nouveau-né de 20 jours. Archives françaises de pédiatrie, $14,615-622$.

Allan, G. W., and Andersen, D. H. (1960). Generalized aspergillosis in an infant 18 days of age. Pediatrics, 26, 432-440.

Frantz, I. D., III, L'Heureux, P., Engel, R. R., and Hunt, C. E. (1975). Necrotizing enterocolitis. Journal of Pediatrics, 86, 259-263.

Hopkins, G. B., Gould, V. E., Stevenson, J. K., and Oliver, T. K., Jr (1970). Necrotizing enterocolitis in premature infants. American Journal of Diseases of Children, 120, 229-232.

Levin, S. E., and Isaacson, C. (1960). Spontaneous perforation of the colon in the newborn infant. Archives of Disease in Childhood, 35, 378-382.
Luke, J. L., Bolande, R. P., and Gross, S. (1963). Generalized aspergillosis and aspergillus endocarditis in infancy. Report of a case. Pediatrics, 31, 115-122.

Matturri, L., and Fasolis, S. (1962). L'aspergillosi generalizzata neonatale (Osservazione anatomopathologica di un caso e revisione della letteratura). Folia hereditaria et pathologica, 12, 87-107.

Pochaczevsky, R., and Kassner, E. G. (1971). Necrotizing enterocolitis of infancy. American Journal of Roentgenology. Radium Therapy, and Nuclear Medicine, 113, 283-296.

Riley, H. D. (1972). Systemic mycoses in children. Current Problems in Pediatrics, 2, 3-38.

Stevenson, J. K., Oliver, T. K., Jr, Graham, C. B., Bell, R. S., and Gould, V. E. (1971). Aggressive treatment of neonatal necrotizing enterocolitis: 38 patients with 25 survivals. Journal of Pediatric Surgery, 6, 28-35.

Virnig, N. L., and Reynolds, J. W. (1974). Epidemiological aspects of neonatal necrotizing enterocolitis. American Journal of Diseases of Children, 128, 186-190.

Zimmerman, L. E. (1955). Fatal fungus infections complicating other diseases. American Journal of Clinical Pathology, 25, 46-65.

Correspondence to Dr H. H. Mangurten, High-Risk Nursery, Lutheran General Hospital, 1775 West Dempster Street, Park Ridge, Illinois 60068, USA. 